University of Texas Rio Grande Valley

ScholarWorks @ UTRGV

Chemistry Faculty Publications and

Presentations

College of Sciences

$5-9-2008$

\title{
Correlation Between Luminescent Properties and Local Coordination Environment for Erbium Dopant in Yttrium Oxide Nanotubes
}

\author{
Yuanbing Mao \\ The University of Texas Rio Grande Valley, yuanbing.mao@utrgv.edu \\ John Bargar \\ Michael Toney \\ Jane P. Chang
}

Follow this and additional works at: https://scholarworks.utrgv.edu/chem_fac

Part of the Chemistry Commons

\section{Recommended Citation}

Mao, Y., Bargar, J., Toney, M., \& Chang, J. P. (2008). Correlation between luminescent properties and local coordination environment for erbium dopant in yttrium oxide nanotubes. Journal of Applied Physics, 103(9), 094316. https://doi.org/10.1063/1.2912486

This Article is brought to you for free and open access by the College of Sciences at ScholarWorks @ UTRGV. It has been accepted for inclusion in Chemistry Faculty Publications and Presentations by an authorized administrator of ScholarWorks@ UTRGV. For more information, please contact justin.white@utrgv.edu,william.flores01@utrgv.edu. 


\title{
Correlation between luminescent properties and local coordination environment for erbium dopant in yttrium oxide nanotubes
}

\author{
Yuanbing Mao, ${ }^{1}$ John Bargar, ${ }^{2}$ Michael Toney, ${ }^{2}$ and Jane P. Chang ${ }^{1, a)}$ \\ ${ }^{1}$ Department of Chemical and Biomolecular Engineering, University of California, \\ Los Angeles, California 90095, USA \\ ${ }^{2}$ Stanford Synchrotron Radiation Laboratory, Stanford Linear Accelerator Center, \\ Stanford, California 94309, USA
}

(Received 21 November 2007; accepted 27 February 2008; published online 9 May 2008)

\begin{abstract}
The local dopant coordination environment and its effect on the photoluminescent (PL) spectral features of erbium-doped yttrium oxide nanotubes (NTs) were probed by synchrotron-based x-ray diffraction (XRD), x-ray absorption near-edge spectroscopy (XANES), and extended x-ray absorption fine structure (EXAFS). XRD, XANES, and EXAFS data demonstrate that single phase solid solutions of $\mathrm{Y}_{(2-x)} \mathrm{Er}_{x} \mathrm{O}_{3}$ were formed at $0 \leq x<0.4$ and $1.2<x \leq 2$, and the valence state of $\mathrm{Er}$ ions in the $\mathrm{Y}_{2} \mathrm{O}_{3}$ NTs is +3 . The $\mathrm{x}$-ray spectroscopic data clearly show that the erbium dopants largely reside in two types of sites in the $\mathrm{Y}_{2} \mathrm{O}_{3}$ host material, both of which possess a well-defined intermediate-range structure, and that the doping of erbium into $\mathrm{Y}_{2} \mathrm{O}_{3}$ does not cause a loss in intermediate-range order and crystallinity in the $\mathrm{Er}^{3+}: \mathrm{Y}_{2} \mathrm{O}_{3}$ NTs. This well-defined distribution of erbium doping inside the $\mathrm{Y}_{2} \mathrm{O}_{3}$ matrix correlates well with the observed sharp and well-resolved PL behavior of these $\mathrm{Er}^{3+}: \mathrm{Y}_{2} \mathrm{O}_{3} \mathrm{NTs}$ at around $1.535 \mu \mathrm{m}$. (C) 2008 American Institute of Physics.
\end{abstract}

[DOI: $10.1063 / 1.2912486]$

\section{INTRODUCTION}

Luminescent materials have many practical applications in devices involving the artificial production of light. Fiberoptic amplifiers, lasers, waveguides, $x$-ray imaging, bioimaging, field emission, and electroluminescent displays are wellknown examples. ${ }^{1,2}$ To improve luminescent characteristics, such as the luminescent efficiency and resolution of images in lighting and display, extensive research has been carried out on rare-earth (RE) ion doped luminescent materials due to the unique luminescent characteristics of RE dopants and their stability in high vacuum. ${ }^{3}$ Lately, luminescent materials with particle dimensions in the nanometer regime have attracted intense research interest since luminescent properties were reported to be dependent on the size and morphology of the crystallites. ${ }^{4,5}$ Therefore, our as-synthesized trivalent erbium-doped yttrium oxide $\left(\mathrm{Er}^{3+}: \mathrm{Y}_{2} \mathrm{O}_{3}\right)$ nanotubes ${ }^{6}$ (NTs) take advantage of the characteristic optical properties of erbium ions and offer the potential size- and morphologyinduced enhancement in luminescent properties, thereby enabling better luminescent materials for advanced luminescent and photonic applications, such as optical amplifiers, lasers, and infrared detectors. ${ }^{7}$

There are a few fundamental issues that need to be solved for advanced luminescent materials with enhanced luminescent characteristics. ${ }^{1,8}$ First, the selection of a favorable host material is critical. ${ }^{1,9}$ In this work, $\mathrm{Y}_{2} \mathrm{O}_{3}$ is selected as a favorable host material for erbium ion substitution due to the following reasons: (1) $\mathrm{Er}_{2} \mathrm{O}_{3}$ and $\mathrm{Y}_{2} \mathrm{O}_{3}$ have identical cubic bixbyite crystal structures with very similar lattice constants and $\mathrm{Y}^{3+}$ and $\mathrm{Er}^{3+}$ ions have nearly the same ionic radii; (2) $\mathrm{Y}_{2} \mathrm{O}_{3}$ is a refractory oxide that has a high melting point

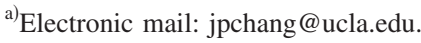

$\left(\sim 2400{ }^{\circ} \mathrm{C}\right)$, a very high thermal conductivity $\left(\kappa_{\mathrm{Y}_{2} \mathrm{O}_{3}}\right.$ $=27 \mathrm{~W} / \mathrm{mK})$, chemical stability, optical isotropicity with a refractive index of 1.91, and low phonon energies $\left(380 \mathrm{~cm}^{-1}\right),{ }^{4}$ which translate to lower nonradiative transition rates and, thus, higher quantum efficiencies of their optical transitions. Second, the design of a desirable preparation procedure is crucial, as it determines the charge state of the RE ions and local coordination environments around the dopants. ${ }^{8,10,11}$ We used a hydrothermal procedure followed by a dehydration process to prepare the $\mathrm{Er}^{3+}: \mathrm{Y}_{2} \mathrm{O}_{3}$ NTs. ${ }^{6}$ It is well known that the hydrothermal process is a relatively low-temperature method that is suited for large scale syntheses of many materials and usually provides highly crystalline products. More importantly, as we will demonstrate, this procedure was able to retain the optically active trivalent state of erbium ions from its precursor state. ${ }^{6}$ Last but not least, the dopant location and distribution in the host material needs to be precisely controlled. This will eliminate the possibility of forming RE ion clusters and/or irregular distribution of RE ions in different crystallographic sites (i.e., interstitial sites). Doped luminescent materials that satisfy these standards usually have higher photoluminescent (PL) efficiencies and better-resolved PL spectra than those that do not. However, the effect of the local coordination environments on the origins of the PL spectral features in nanosized RE-doped oxide systems has not been quantified. ${ }^{10,12-15}$

It is well known that much of the controversy on PL characteristics has stemmed from irregular distribution, clustering, or phase segregation of the RE dopant ions or unbonded surface dopant ions, which can result in broad PL peaks and a low PL efficiency. ${ }^{16}$ Even in systems that appear to be quite pure and highly crystalline, reported PL behaviors widely vary. This variance in PL features is attributed to the 
multitude of synthetic methods used for the production of RE ion doped oxide materials, which can result in differences in the dopant environment and/or structural disorder. ${ }^{6,10,12,13}$ Previously, high-resolution transmission electron microscopy (TEM) associated with energy-dispersive x-ray spectroscopy and electron diffraction enabled researchers to determine the structure of the host materials but failed to show exactly where the RE ions reside. ${ }^{6,8}$ Therefore, in order to extract more accurate information regarding the local coordination environments and the origins of the PL spectral features from our as-synthesized $\mathrm{Er}^{3+}: \mathrm{Y}_{2} \mathrm{O}_{3} \mathrm{NTs}$, it is vital to perform a rigorous structural characterization.

$\mathrm{X}$-ray diffraction (XRD) is widely applied to determine the long-range structure of crystalline materials. In the case of materials with moderate to long-range order, the diffraction patterns contain information about the atomic structure (intensities), strain (peak positions), and the particle size (peak widths). In particular, synchrotron-based XRD offers an exceptional resolution and sensitivity, even on very small/ thin samples. This permits the identification and quantification of trace phases in RE ion doped materials. On the other hand, x-ray absorption spectroscopy (XAS), including x-ray absorption near-edge structure (XANES) and extended $\mathrm{x}$-ray absorption fine structure (EXAFS), is a well-known spectroscopic technique based on the excitation of electrons from an inner level to outer unoccupied states as the result of absorbing X-ray energy. ${ }^{17,18}$ It is sensitive to the local structure and to the partial empty density of states. As a consequence, XAS has been extensively used to investigate the local structure in bulk systems and at the surface of materials to yield information on the local electronic structure and the coordination environment around an absorbing atom. ${ }^{19}$ In recent years, XAS has also been recognized as a powerful probe for determining the local structure around impurities in nanocrystals because of its sensitivity to the short-range order and atomic species surrounding an absorbing site. ${ }^{11,20-23}$ XANES is sensitive to the valence state and coordination polyhedra and EXAFS provides precise information about the average structural parameters of a selected element in a complex material, including neighboring coordination numbers and bond lengths. Therefore, we use a combination of complementary synchrotron-based XRD and XAS techniques to study the structural characteristics of these $\mathrm{Er}^{3+}: \mathrm{Y}_{2} \mathrm{O}_{3}$ NTs. This provides insight into the local coordination environments and the origins of the PL spectral features of these nanostructured samples, from the long-range order down to the local environment of the trivalent erbium cations.9,11,24-26 Although these types of experiments have been previously conducted on bulk, thin film, and nanoparticle systems of some RE ion doped oxide materials, only a few studies using synchrotronbased analysis of RE-doped NT oxides have been reported. ${ }^{5,12-15}$

\section{EXPERIMENT}

\section{A. Sample preparation}

The $\mathrm{Er}^{3+}: \mathrm{Y}_{2} \mathrm{O}_{3}$ NTs used in this study were synthesized as previously reported. ${ }^{6}$ Specifically, high-purity $\mathrm{Y}\left(\mathrm{NO}_{3}\right)_{3}$ and $\mathrm{Er}\left(\mathrm{NO}_{3}\right)_{3}$ (a total of $1.5 \mathrm{mmol}$, with a specifically ad- justed $\mathrm{Y}^{3+} / \mathrm{Er}^{3+}$ molar ratio) were dissolved in $4 \mathrm{ml} \mathrm{de-}$ ionized $\mathrm{H}_{2} \mathrm{O}$, followed by the dropwise addition of $14 \mathrm{ml}$ of $1-2 M \mathrm{NaOH}$ solution under stirring. After being stirred for $1 \mathrm{~h}$, the milky colloid solution was transferred into a $23 \mathrm{ml}$ Teflon-lined autoclave and subsequently sealed and heated at $130{ }^{\circ} \mathrm{C}$ for $7 \mathrm{~h}$. The resulting reaction solution along with the precipitate was naturally cooled down to room temperature and then centrifuged. The colorless supernatant, which included the reaction by-products, was discarded. The precipitate was washed with de-ionized water several times and then dried at $80{ }^{\circ} \mathrm{C}$ overnight. Finally, the obtained powder of $\mathrm{Er}^{3+}: \mathrm{Y}(\mathrm{OH})_{3} \mathrm{NTs}$ was placed into a ceramic crucible and converted into corresponding powder of $\mathrm{Er}^{3+}: \mathrm{Y}_{2} \mathrm{O}_{3}$ NTs by annealing at $500{ }^{\circ} \mathrm{C}$ for $3 \mathrm{~h}$ in a box furnace. In this study, seven $\mathrm{Er}^{3+}: \mathrm{Y}_{2} \mathrm{O}_{3} \mathrm{NT}$ samples were prepared with doping levels of $0 \%\left(\mathrm{Y}_{2} \mathrm{O}_{3}\right), 5 \%\left(\mathrm{Y}_{1.9} \mathrm{Er}_{0.1} \mathrm{O}_{3}\right), 10 \%\left(\mathrm{Y}_{1.8} \mathrm{Er}_{0.2} \mathrm{O}_{3}\right)$, $20 \%\left(\mathrm{Y}_{1.6} \mathrm{Er}_{0.4} \mathrm{O}_{3}\right), 40 \%\left(\mathrm{Y}_{1.2} \mathrm{Er}_{0.8} \mathrm{O}_{3}\right), 60 \%\left(\mathrm{Y}_{0.8} \mathrm{Er}_{1.2} \mathrm{O}_{3}\right)$, and $100 \%\left(\mathrm{Er}_{2} \mathrm{O}_{3}\right)$, which are denoted as E0NT, E5NT, E10NT, E20NT, E40NT, E60NT, and E100NT, respectively. Here, "E" and "NT" stand for "erbium" and "nanotube," respectively, while the numbers in between represent the doping levels of erbium ions.

\section{B. Measurements}

The room temperature PL properties of the $\mathrm{Er}^{3+}: \mathrm{Y}_{2} \mathrm{O}_{3}$ NTs with different doping levels were measured in their powder forms with a $488 \mathrm{~nm} \mathrm{Ar}^{+}$laser operated at $0.5 \mathrm{~W}$. The InGaAs detector was cooled by using liquid nitrogen. To prepare the PL samples, powders of $\mathrm{Er}^{3+}: \mathrm{Y}_{2} \mathrm{O}_{3}$ NTs were added into ethanol, and the mixtures were subsequently sonicated for about $1 \mathrm{~min}$ and later were air dried upon deposition onto silicon wafers. Both synchrotron-based XRD and XAS measurements were conducted at the Stanford Synchrotron Radiation Laboratory (SSRL). The XAS and XRD data from commercial cubic phase $\mathrm{Er}_{2} \mathrm{O}_{3}$ and $\mathrm{Y}_{2} \mathrm{O}_{3}$ powders (99.99\%, from Alfa Aesar and CERAC, Inc., respectively) were also collected as references. Synchrotron-based XRD data were collected in reflection mode on beamline 2-1 by using incident $\mathrm{x}$-ray with a photon energy of $14 \mathrm{keV}(\lambda$ $=0.886 \AA$ ) from $q=1.9$ to $6.3 \AA^{-1}$, where $q$ is the scattering vector. The wavelength calibration was determined based on the diffraction pattern of $\mathrm{LaB}_{6}$. The diffracted beam was analyzed with a $\mathrm{Si}(111)$ crystal. The powder samples of both the $\mathrm{Er}^{3+}: \mathrm{Y}_{2} \mathrm{O}_{3}$ NTs and the references were pressed into a shallow cavity of a quartz sample holder. The loaded samples were rocked throughout the experiment in the X-ray beam. The XAS measurements of the Er $L_{\mathrm{III}}$-edge and Y $K$-edge radiation for both the $\mathrm{Er}^{3+}: \mathrm{Y}_{2} \mathrm{O}_{3}$ NTs and the references were performed on beamline 11-2. Incident $\mathrm{x}$ rays were monochromatized by using a silicon (220) double-crystal monochromator and were detected by using an ionization chamber filled with $\mathrm{N}_{2}$ gas. XAS spectra were recorded in transmission mode. Harmonic rejection was provided by use of a Rh-coated x-ray mirror. The energy calibration was checked by measuring the spectra of the $0.005 \mu \mathrm{m}$ thick metal foils. 


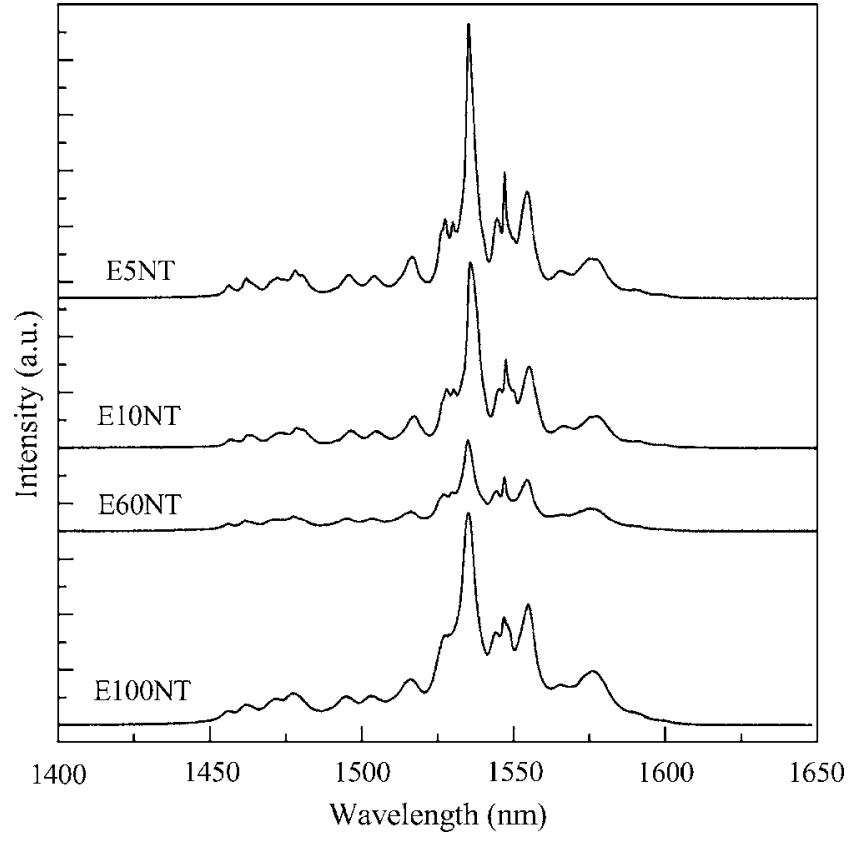

FIG. 1. Room temperature PL spectra of the $\mathrm{Er}^{3+}: \mathrm{Y}_{2} \mathrm{O}_{3}$ NTs with various doping levels after annealing the as-synthesized $\mathrm{Er}^{3+}: \mathrm{Y}(\mathrm{OH})_{3}$ NTs at $500{ }^{\circ} \mathrm{C}$ for $3 \mathrm{~h}$ (offset for clarification). The intensity variation is likely due to the varying amount of NTs sampled for PL measurements.

\section{RESULTS AND DISCUSSION}

\section{A. Photoluminescence}

The maximum intensities of the room temperature PL spectra (Fig. 1) were clearly observed at a wavelength of $\sim 1.535 \mu \mathrm{m}$. These are characteristic of the ${ }^{4} I_{13 / 2} \rightarrow{ }^{4} I_{15 / 2}$ transition of $\mathrm{Er}^{3+}$ ions, with full widths at half maximum of only $\sim 4 \mathrm{~nm}$. These spectra show similar features with those from the $\mathrm{Er}^{3+}: \mathrm{Y}_{2} \mathrm{O}_{3}$ thin film nanostructures prepared by radical-enhanced atomic layer deposition..$^{9,16,27}$ The $\sim 4 \mathrm{~nm}$ full widths at half maximum are much smaller than those of the thin film samples $(\sim 12 \mathrm{~nm}))^{9,16,27}$ In general, spectral broadening would be observed if there were an irregular distribution of $\mathrm{Er}^{3+}$ on crystallographic lattice sites or some of the Er ions occupied defect sites (i.e., interstitial sites). This would randomize the Stark splitting. In this study, these remarkably sharp and well-resolved PL spectra observed from our as-synthesized $\mathrm{Er}^{3+}: \mathrm{Y}_{2} \mathrm{O}_{3}$ NTs at a wavelength of $\sim 1.535 \mu \mathrm{m}$ indicate that erbium cations occupy welldefined locations and retain the optically active trivalent state in the $\mathrm{Y}_{2} \mathrm{O}_{3}$ lattice, namely, those of $\mathrm{Y}^{3+}$ ions, as confirmed by the XRD and XANES analyses discussed in Secs. III B and III C, respectively.

\section{B. XRD}

Synchrotron-based XRD is an effective characterization technique for this work since the XRD diffraction pattern of a phase separated binary mixture would show two sets of distinct peaks corresponding to their pure components, while for a solid solution, only one set of diffraction peaks will be present. ${ }^{26}$ In this work, XRD patterns from the $\mathrm{Er}^{3+}: \mathrm{Y}_{2} \mathrm{O}_{3}$ NTs with different doping levels show that they exhibit only one set of diffraction peaks, which correspond to a cubic

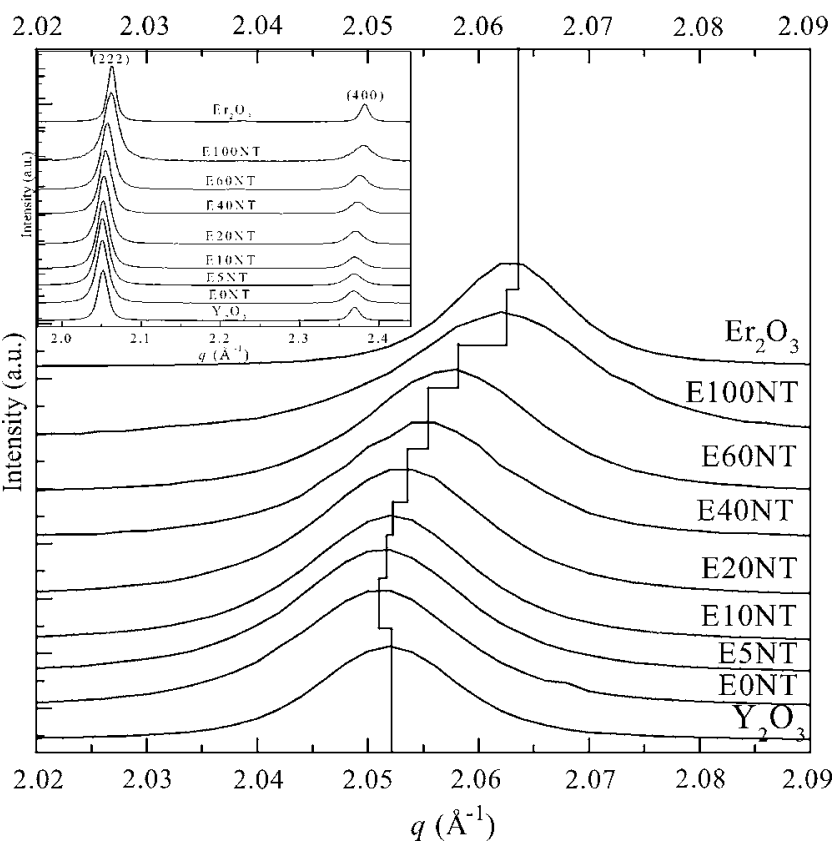

FIG. 2. Synchrotron-based XRD patterns of the commercial $\mathrm{Y}_{2} \mathrm{O}_{3}$ and $\mathrm{Er}_{2} \mathrm{O}_{3}$ powders and of the $\mathrm{Er}^{3+}: \mathrm{Y}_{2} \mathrm{O}_{3}$ NTs with various doping levels after annealing the as-synthesized $\mathrm{Er}^{3+}: \mathrm{Y}(\mathrm{OH})_{3} \mathrm{NTs}$ at $500{ }^{\circ} \mathrm{C}$ for $3 \mathrm{~h}$, which only show the (222) peak to demonstrate the gradual decrease in the $d$ value (increase in the $q$ value) with an increase in doping levels. The inset shows the (222) and (400) peaks of $\mathrm{Er}^{3+}: \mathrm{Y}_{2} \mathrm{O}_{3} \mathrm{NTs}$ with various doping levels with a cubic bixbyite structure.

bixbyite phase (space group number 206, Ia3, Fig. 2). Also, no additional peaks indicating the presence of other phases were found. The diffraction peaks that were indexed match the literature values for $\mathrm{Y}_{2} \mathrm{O}_{3}$ or $\mathrm{Er}_{2} \mathrm{O}_{3}$. Therefore, the assynthesized $\mathrm{Er}^{3+}: \mathrm{Y}_{2} \mathrm{O}_{3}$ NTs are pure single phase solid solutions of $\mathrm{Y}_{2} \mathrm{O}_{3}$ and $\mathrm{Er}_{2} \mathrm{O}_{3}$.

The XRD patterns exhibit considerable line broadening consistent with the fine-particle nature of the $\mathrm{Er}^{3+}: \mathrm{Y}_{2} \mathrm{O}_{3}$ NTs. For the synchrotron-based XRD data from both the as-synthesized $\mathrm{Er}^{3+}: \mathrm{Y}_{2} \mathrm{O}_{3}$ NTs and the references, the Bragg peaks were fitted to Pearson-VII functions and the lattice constants were calculated from a least-squares analysis of the Bragg peak positions. The peak broadening was obtained by measuring the width of the strongest diffraction peak (the 222 reflection) because this reflection does not overlap with others. The Scherrer equation was used in calculating crystallite sizes (microstrain was not considered). The calculated lattice constants and crystallite sizes are summarized in Table I. The calculated crystallite sizes are around $30 \mathrm{~nm}$, which are much smaller than the sizes of the $\mathrm{Er}^{3+}: \mathrm{Y}_{2} \mathrm{O}_{3}$ NTs observed by scanning electron microscopy (SEM) and TEM. From the SEM and TEM images (Fig. 3), these NTs have lengths in the range of $2-5 \mu \mathrm{m}$, outer diameters of $\sim 100-400 \mathrm{~nm}$, and inner diameters of 50-100 $\mathrm{nm}$. These indicate that these $\mathrm{Er}^{3+}: \mathrm{Y}_{2} \mathrm{O}_{3}$ NTs are polycrystalline. Figure 2 also shows the gradual decrease in the $d$ value (corresponding to a gradual decrease in the lattice constant $a$ ) as a function of Er concentration, as would be expected with the substitution of the smaller $\mathrm{Er}^{3+}$ cation $(\sim 0.89 \AA)$ for the $\mathrm{Y}^{3+}$ cation $(\sim 0.90 \AA)$. For both pure $\mathrm{Y}_{2} \mathrm{O}_{3}$ and $\mathrm{Er}_{2} \mathrm{O}_{3}$ NTs, there is a small increase in the lattice constant compared to the 
TABLE I. Lattice constants and crystallite sizes obtained from synchrotron XRD studies of the $\mathrm{Er}^{3+}: \mathrm{Y}_{2} \mathrm{O}_{3}$ NTs with various doping levels after annealing the as-synthesized $\mathrm{Er}^{3+}: \mathrm{Y}(\mathrm{OH})_{3} \mathrm{NTs}$ at $500{ }^{\circ} \mathrm{C}$ for $3 \mathrm{~h}$ as well as those from commercial $\mathrm{Y}_{2} \mathrm{O}_{3}$ and $\mathrm{Er}_{2} \mathrm{O}_{3}$ powders.

\begin{tabular}{lcc}
\hline \hline \multicolumn{1}{c}{ Sample composition } & $\begin{array}{c}\text { Lattice constant } \\
(\AA)\end{array}$ & $\begin{array}{c}\text { Crystallite size } \\
(\mathrm{nm})\end{array}$ \\
\hline $\mathrm{Y}_{2} \mathrm{O}_{3}{ }^{\mathrm{a}}$ & 10.6041 & $\ldots$ \\
$\mathrm{Y}_{2} \mathrm{O}_{3}$ powder & 10.6075 & 47 \\
$\mathrm{Y}_{2} \mathrm{O}_{3} \mathrm{NTs}$ & 10.6122 & 33 \\
$\mathrm{Y}_{1.9} \mathrm{Er}_{0.1} \mathrm{O}_{3} \mathrm{NTs}$ & 10.6106 & 25 \\
$\mathrm{Y}_{1.8} \mathrm{Er}_{0.2} \mathrm{O}_{3} \mathrm{NTs}$ & 10.6070 & 29 \\
$\mathrm{Y}_{1.6} \mathrm{Er}_{0.4} \mathrm{O}_{3} \mathrm{NTs}$ & 10.6019 & 36 \\
$\mathrm{Y}_{1.2} \mathrm{Er}_{0.8} \mathrm{O}_{3} \mathrm{NTs}$ & 10.5910 & 31 \\
$\mathrm{Y}_{0.8} \mathrm{Er}_{1.2} \mathrm{O}_{3} \mathrm{NTs}$ & 10.5792 & 37 \\
$\mathrm{Er}_{2} \mathrm{O}_{3} \mathrm{NTs}$ & 10.5566 & 25 \\
$\mathrm{Er}_{2} \mathrm{O}_{3}$ powder & 10.5510 & 53 \\
$\mathrm{Er}_{2} \mathrm{O}_{3}{ }^{\text {b }}$ & 10.5400 & $\cdots$ \\
\hline \hline
\end{tabular}

${ }^{\mathrm{a}}$ Reference 36.

${ }^{\mathrm{b}}$ Reference 37.

JCPDS information and commercial powders. The commercial powders are micron-sized particles (SEM images not shown), which are composed of nanosized particles, as confirmed by particle size calculation based on the Scherrer equation. This small increase in the lattice constant $a$ for all NT samples is attributed to the fact that they are composed of small particles. Nevertheless, we could not rule out the possible interstitial coordination of $\mathrm{Er}^{3+}$ ions from these XRD data. Also, it is possible that the doping induces a localized distortion of the lattice around the dopant. To elucidate the origin, we performed XANES and $\operatorname{Er} L_{\mathrm{III}}$-edge EXAFS spectroscopic analyses.

\section{XANES}

The XANES regions of the x-ray absorption spectrum contain electronic information on the immediate environment of the absorbing atom that, in principle, can be translated into geometrical information. The peak position and the line shape of the spectrum depend on the local electronic structure of the studied ion, providing information on its valence state and site symmetry. ${ }^{11,14}$ This information complements that provided by the EXAFS region, which is restricted to interatomic distances. For XANES, data reduction of the XAS measurements were performed with the SIXPACK program by following standard procedures described elsewhere. ${ }^{9,28}$ Threshold energy values (at $\left.k=0\right), E_{0}$,
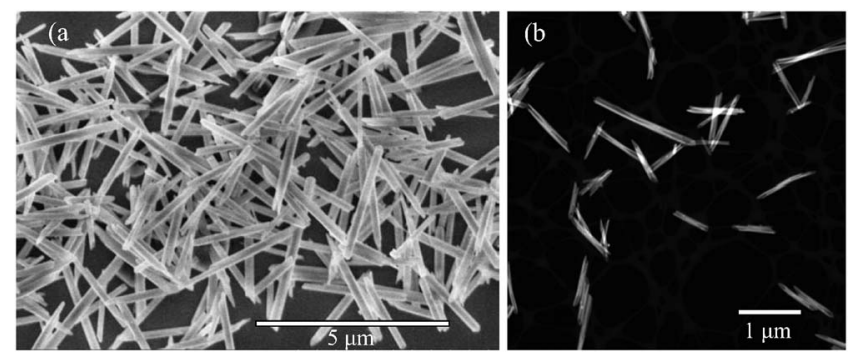

FIG. 3. (a) SEM and (b) high-angle annular dark field TEM images of the $5 \% \mathrm{Er}^{3+}: \mathrm{Y}_{2} \mathrm{O}_{3} \mathrm{NTs}$, respectively, after annealing the as-synthesized $\mathrm{Er}^{3+}: \mathrm{Y}(\mathrm{OH})_{3} \mathrm{NTs}$ at $500{ }^{\circ} \mathrm{C}$ for $3 \mathrm{~h}$.

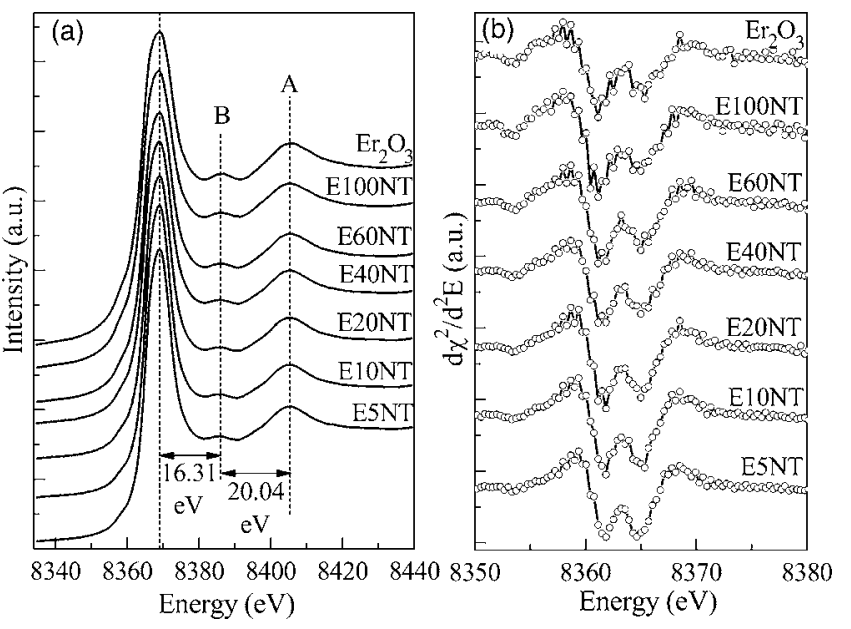

FIG. 4. As-prepared $\mathrm{Er}^{3+}: \mathrm{Y}_{2} \mathrm{O}_{3}$ NTs with various doping levels after annealing the as-synthesized $\mathrm{Er}^{3+}: \mathrm{Y}(\mathrm{OH})_{3} \mathrm{NTs}$ at $500{ }^{\circ} \mathrm{C}$ for $3 \mathrm{~h}$ and the commercial $\mathrm{Er}_{2} \mathrm{O}_{3}$ powder: (a) $\mathrm{Er} L_{\mathrm{III}}$-edge XANES spectra and (b) second derivatives of the white lines of the Er $L_{\mathrm{III}}$-edge XANES spectra shown in (a). The spectra in both panels were offset for clarification.

were assigned as $8.365 \mathrm{eV}$ for the $\operatorname{Er} L_{\mathrm{III}}$ edge by using the reference $\mathrm{Er}_{2} \mathrm{O}_{3}$ powder sample and $17.050 \mathrm{eV}$ for the $\mathrm{Y} K$-edge by using the reference $\mathrm{Y}_{2} \mathrm{O}_{3}$ powder sample. Figure 4(a) shows the XANES at the Er $L_{\text {III }}$ edge for the $\mathrm{Er}^{3+}: \mathrm{Y}_{2} \mathrm{O}_{3} \mathrm{NTs}$ and commercial $\mathrm{Er}_{2} \mathrm{O}_{3}$ powder. In Fig. 4(a), the principal $\mathrm{x}$-ray absorption peak appearing at the lower energy side of the $\operatorname{Er} L_{\mathrm{III}}$ absorption edge is assigned as the "white line," with a pronounced peak at the threshold. The position and intensity of the white line is governed by the electron transition from erbium $2 p_{2 / 3}$ to the erbium $4 f 5 d$ final state and is sensitive to the valence state of the absorbing erbium ions as well as their chemical environment. ${ }^{19}$ These peaks from all of the $\mathrm{Er}^{3+}: \mathrm{Y}_{2} \mathrm{O}_{3} \mathrm{NT}$ and commercial $\mathrm{Er}_{2} \mathrm{O}_{3}$ powder samples have the same shape and position. Therefore, the valence state of Er ions in the doped $\mathrm{Y}_{2} \mathrm{O}_{3}$ NTs is +3 and the $\mathrm{Er}^{3+}$ ions in the $\mathrm{Er}^{3+}: \mathrm{Y}_{2} \mathrm{O}_{3}$ NTs possess a chemical environment similar to those in the commercial $\mathrm{Er}_{2} \mathrm{O}_{3}$ powder.

For the commercial $\mathrm{Er}_{2} \mathrm{O}_{3}$ powder, the shape resonance curve exhibits a broad peak (peak A, $36.35 \mathrm{eV}$ higher than the white line) plus a small shoulder peak (peak B, $16.31 \mathrm{eV}$ higher than the white line). The oscillation peak labeled A in Fig. 4(a) is the first EXAFS oscillation and is dominated by Er-O single scattering. ${ }^{14}$ Peak B contains single and multiple scattering contributions. Its presence indicates that Er resides in a site possessing a well-defined intermediate-to-longrange structure. ${ }^{5,8,14,29,30}$ Thus, the presence of this peak in $\mathrm{Er}^{3+}: \mathrm{Y}_{2} \mathrm{O}_{3} \mathrm{NT}$ samples indicates well-defined structural order around erbium in these materials, even though a relatively low annealing temperature of $500{ }^{\circ} \mathrm{C}$ was applied to the initial $\mathrm{Er}^{3+}: \mathrm{Y}(\mathrm{OH})_{3} \mathrm{NTs}^{8}$ Specifically, the similarity of both the $\mathrm{A}$ and the $\mathrm{B}$ peaks from the spectra of these $\mathrm{Er}^{3+}: \mathrm{Y}(\mathrm{OH})_{3}$ NTs to that of the commercial $\mathrm{Er}_{2} \mathrm{O}_{3}$ powder indicates that both materials have a similar local structural environment around $\mathrm{Er}$, with a similar degree of order and are independent of the erbium doping levels.

As shown in Fig. 4(b), the second derivatives of the Er $L_{\mathrm{III}}$-edge XANES spectra for the $\mathrm{Er}^{3+}: \mathrm{Y}_{2} \mathrm{O}_{3}$ NTs and the 


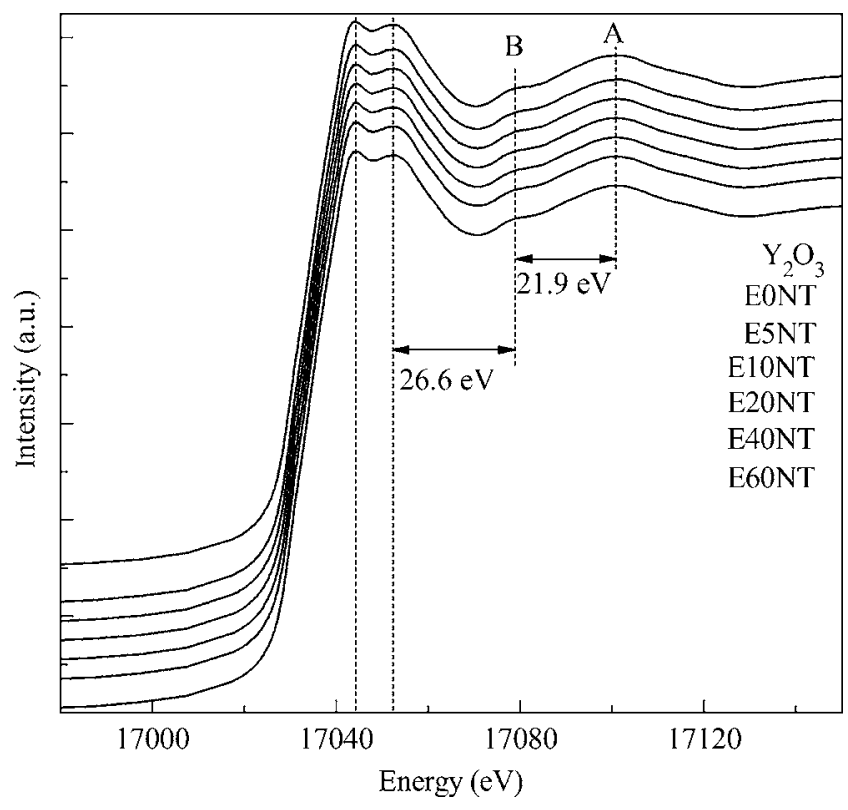

FIG. 5. Y $K$-edge XANES spectra of the $\mathrm{Er}^{3+}: \mathrm{Y}_{2} \mathrm{O}_{3}$ NTs with various doping levels after annealing the as-synthesized $\mathrm{Er}^{2+}: \mathrm{Y}(\mathrm{OH})_{3} \mathrm{NTs}$ at $500{ }^{\circ} \mathrm{C}$ for $3 \mathrm{~h}$ and of the commercial $\mathrm{Y}_{2} \mathrm{O}_{3}$ powder (offset for clarification).

commercial $\mathrm{Er}_{2} \mathrm{O}_{3}$ powder were plotted. These data are useful for separating and identifying complex spectra because it highlights the features around the absorbing $\operatorname{Er} L_{\mathrm{III}}$ edge. ${ }^{31}$ They are clearly split into doublets, which indicates that the resonant peaks of $\mathrm{Er}-\mathrm{O}$ for these $\mathrm{Er}^{3+}: \mathrm{Y}_{2} \mathrm{O}_{3}$ NTs and the commercial $\mathrm{Er}_{2} \mathrm{O}_{3}$ powder probably originate from two electronic states related to the $4 f 5 d$ orbitals. These data further identified the similarity in terms of the valence state of $\mathrm{Er}$ ions, level of structural disorder, and coordination polyhedron between the commercial $\mathrm{Er}_{2} \mathrm{O}_{3}$ powder and the assynthesized $\mathrm{Er}^{3+}: \mathrm{Y}_{2} \mathrm{O}_{3}$ NTs.

Figure 5 shows the XANES at the $\mathrm{Y} K$-edge of the $\mathrm{Er}^{3+}: \mathrm{Y}_{2} \mathrm{O}_{3}$ NTs and commercial $\mathrm{Y}_{2} \mathrm{O}_{3}$ powder. No energy shift is observed in the absorbing $\mathrm{Y} K$ edge between the commercial $\mathrm{Y}_{2} \mathrm{O}_{3}$ powder and the $\mathrm{Er}^{3+}: \mathrm{Y}_{2} \mathrm{O}_{3}$ NTs, which indicates that the $\mathrm{Y}$ cations in the $\mathrm{Er}^{3+}: \mathrm{Y}_{2} \mathrm{O}_{3}$ NTs are also trivalent. The double peak structure is due to a splitting of the $p$ orbitals by the distorted octahedral geometry around $\mathrm{Y}^{32}$ The oscillation peaks A and B at the higher energy side of the white lines in the XANES spectra at the $\mathrm{Y} K$ edge have the same shape and position, which indicates that the levels of structural disorder in these $\mathrm{Er}^{3+}: \mathrm{Y}_{2} \mathrm{O}_{3}$ NTs are similar to the structural disorder level in the commercial cubic phase $\mathrm{Y}_{2} \mathrm{O}_{3}$ powder.

\section{EXAFS and its fitting}

The EXAFS spectra were analyzed and modeled by using the standard EXAFS equation and procedure. ${ }^{5,14,17}$ In modeling the $\mathrm{Er} L_{\mathrm{III}}$-edge EXAFS, theoretical backscattering amplitudes of up to $4 \AA$ radial distance from the center absorbing Er were first calculated by using FEFF $6 \mathrm{~L} .{ }^{9}$ The lattice parameters and the atomic coordinates used for the FEFF calculation were obtained from the crystal structure in the ICSD database. ${ }^{33,34}$ Both bulk $\mathrm{Er}_{2} \mathrm{O}_{3}$ and $\mathrm{Y}_{2} \mathrm{O}_{3}$ have a cubic bixbyite structure, which belongs to the space group Ia3 $-T_{h}^{7}$,
$Z=16$. The unit cell for this structure consists of 32 metal ions, each coordinated with six $\mathrm{O}$. This bixbyite structure has two nonequivalent symmetry sites available for the metal ions. Specifically, 24 of the 32 metal ions reside in the $C_{2}$ symmetry site with the two missing $\mathrm{O}$ lying on the face diagonal, resulting in two slightly different metal-oxygen bonds. The remaining eight metal ions are in the $C_{3 i}$ symmetry site where the two missing $\mathrm{O}$ lie on the body diagonal, yielding six equivalent metal-oxygen bonds. The Er-O bond lengths for the $C_{2}$ site are 2.246 and $2.334 \AA$, whereas that for the $C_{3 i}$ sites is $2.263 \AA$. In our fittings, these differences in the cationic site symmetry $\left(C_{2}: C_{3 i}=3: 1\right)$ and the Er-O bond length are manifested as a split oxygen shell, with an average coordination of $4.5 \mathrm{O}$ at $2.256 \AA$ and $1.5 \mathrm{O}$ at $2.334 \AA$. Consequently, the second shell (Er to $\mathrm{Er}$ as the second nearest neighbor with a total coordination number of 12) is also a split shell, consisting of six $\mathrm{Er}^{3+}$ ions at $3.496 \AA$ and six $\mathrm{Er}^{3+}$ ions at $3.985 \AA$.

Results from the FEFF calculations were used to fit unsmoothed background-subtracted $k^{3}$-weighted EXAFS spectra. Quantitative curve fitting were done in the $R$ space over the same $R$ range from 1.0 to $4.5 \AA$. In addition, the first and second coordination shells were simultaneously used in the fit. Specifically, the following single scattering paths were defined: First shell. $\mathrm{Er} \leftrightarrow \mathrm{O}_{j}$ path described by a bond length $R_{\mathrm{Er} \leftrightarrow \mathrm{O}_{j}}$ with a Debye-Waller factor $\sigma_{\mathrm{O}_{j}}^{2}$. Second shell. $\mathrm{Er} \leftrightarrow M_{k}$ path at a distance length $D_{\mathrm{Er} \leftrightarrow M_{k}}$ with a DebyeWaller factor $\sigma_{M_{k}}^{2}$, where the subscripts $j$ and $k$ denotes $\mathrm{O}$ and $M$ at different $R$ and $D$ to the center absorbing Er. $^{9}$ In this case, two single scattering paths $(j=1$ and 2$)$ at 2.26 and $2.33 \AA$ were used to describe the first split $\mathrm{O}$ shell. Due to their similar coordination environments and a small difference in bond lengths (within $0.07 \AA$ ), only one DebyeWaller factor was used for the first shell $\left(\sigma_{\mathrm{O}_{1}}^{2}=\sigma_{\mathrm{O}_{2}}^{2}=\sigma_{\mathrm{O}}^{2}\right)$. Interactions with the second shell were also described by two scattering paths, each initially set at $D_{\mathrm{Er} \leftrightarrow M 1}=3.50 \AA$ and $D_{\mathrm{Er} \leftrightarrow M 2}=3.99 \AA$ with Debye-Waller factors of $\sigma_{M 1}^{2}$ and $\sigma_{M 2}^{2}$, respectively. The structural parameters were then allowed to refine by letting $R, D, \sigma_{\mathrm{O}}^{2}$, and $\sigma_{M_{k}}^{2}$ adjust until a best fit with the lowest residual value was obtained. The best fits were derived judging from the residual factor $R_{\text {res }}$,

$$
R_{\mathrm{res}}=\sum_{i}\left[k^{3}\left(\chi_{i}^{\mathrm{expt}}-\chi_{i}^{\mathrm{calc}}\right)\right]^{2},
$$

where $\chi_{i}^{\text {expt }}$ and $\chi_{i}^{\text {calc }}$ are the experimental and fitting EXAFS spectra, respectively.

An EXAFS analysis on the commercial $\mathrm{Er}_{2} \mathrm{O}_{3}$ powder reference was first performed in order to establish a structural reference required for determining the chemical identities, coordination numbers, and bond lengths in the $\mathrm{Er}^{3+}: \mathrm{Y}_{2} \mathrm{O}_{3}$ NTs samples and also to assess the accuracy of FEFF fittings. The EXAFS spectrum of the commercial $\mathrm{Er}_{2} \mathrm{O}_{3}$ powder reference was analyzed on the basis of the $\mathrm{Er}_{2} \mathrm{O}_{3}$ crystal structure and the single scattering paths mentioned earlier. As shown in Figs. 6 and 7 (solid line), fairly good fits in terms of the oscillation frequency were obtained with this model for commercial $\operatorname{Er}_{2} \mathrm{O}_{3}$ powder sample. The extracted bond lengths and coordination numbers for the first 


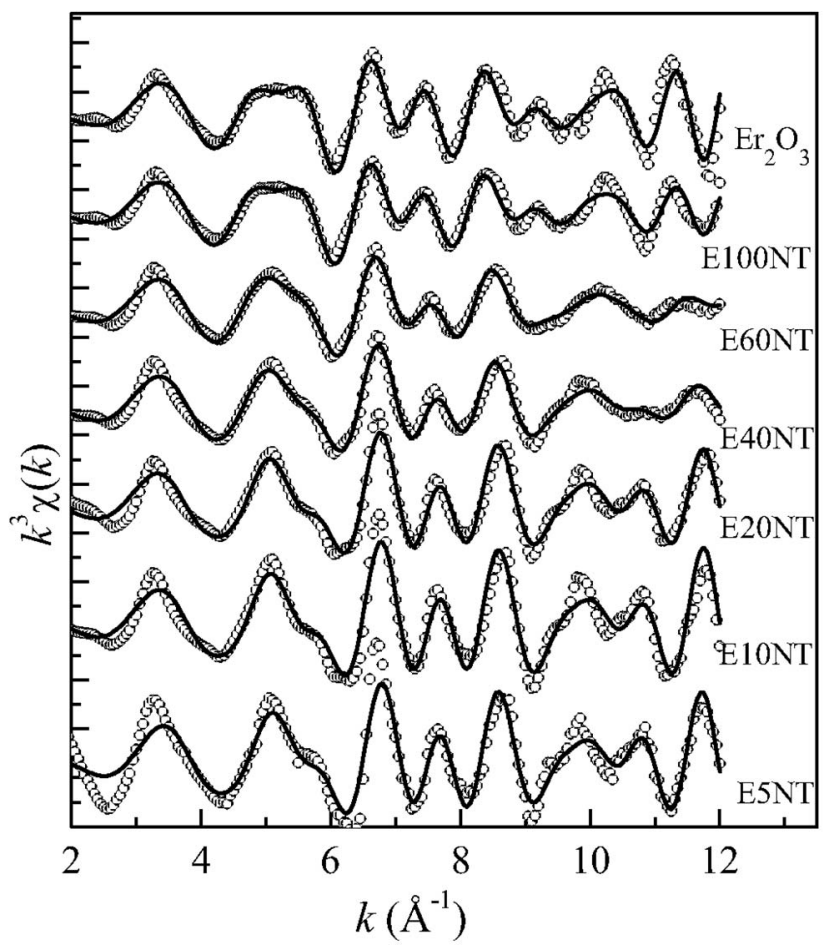

FIG. 6. $k^{3}$-weighted Er $L_{\mathrm{III}}$-edge EXAFS (points) and its corresponding fits (lines) of the $\mathrm{Er}^{3+}: \mathrm{Y}_{2} \mathrm{O}_{3}$ NTs with various doping levels after annealing the as-synthesized $\mathrm{Er}^{3+}: \mathrm{Y}(\mathrm{OH})_{3} \mathrm{NTs}$ at $500{ }^{\circ} \mathrm{C}$ for $3 \mathrm{~h}$ and of the commercial $\mathrm{Er}_{2} \mathrm{O}_{3}$ powder.

and second shells are in excellent agreement with the reported values (Table II). From these fits, the amplitude reduction factor of $\mathrm{Er}^{3+}$ was determined to be 0.91 , which is fairly reasonable for heavy elements; $;{ }^{9,16,27}$ thus, it is set at this value in the subsequent analyses of the $\mathrm{Er}^{3+}: \mathrm{Y}_{2} \mathrm{O}_{3}$ NT samples. Moreover, the results show that the multiple scattering signals can be neglected above $4 \AA$. Therefore, we consider only the single scattering paths in the analysis of the EXAFS spectra of our $\mathrm{Er}^{3+}: \mathrm{Y}_{2} \mathrm{O}_{3}$ NT samples.

For all of the $\mathrm{Er}^{3+}: \mathrm{Y}_{2} \mathrm{O}_{3}$ NT samples, the coordination number for each shell was fixed according to the $\mathrm{Er}_{2} \mathrm{O}_{3}$ crystal structural data and the occupancy fraction of all $\mathrm{Er}$ in the material comprised by Er atoms having sites with an $\mathrm{Er}_{2} \mathrm{O}_{3}$ local structure was fixed to unity. ${ }^{9}$ The interatomic distance and the Debye-Waller factor for each shell and the refined correction of Fermi energy in vacuum $e_{0}$ for $\mathrm{Er} \leftrightarrow \mathrm{O}$ and $\operatorname{Er} \leftrightarrow \operatorname{Er}(\mathrm{Y})$ were allowed to vary in the fitting procedure. All of the spectra were treated in exactly the same manner, and the validity of the data reduction and fitting procedures was checked against the spectra of the reference $\mathrm{Er}_{2} \mathrm{O}_{3}$ and $\mathrm{Y}_{2} \mathrm{O}_{3}$ compounds. The refinements were carried out to minimize the fitting residue factor $R_{\text {res }}$. Figure 6 shows the $\mathrm{Er} L_{\mathrm{III}}$-edge EXAFS functions $k^{3} \chi(k)$ of the $\mathrm{Er}^{3+}: \mathrm{Y}_{2} \mathrm{O}_{3}$ NT samples with different doping levels along with the commercial $\operatorname{Er}_{2} \mathrm{O}_{3}$ powder sample. It is obvious that for the $\mathrm{Er} L_{\mathrm{III}}$ edge, the NT spectra are generally similar to one another and slightly differ from those of the commercial $\mathrm{Er}_{2} \mathrm{O}_{3}$ powder reference. This observation suggests that $\mathrm{Er}^{3+}$ ions enter the lattice of $\mathrm{Y}_{2} \mathrm{O}_{3}$ to substitute at $\mathrm{Y}^{3+}$ sites instead of forming $\mathrm{Er}_{2} \mathrm{O}_{3}$ clusters or nanocrystalline domains that are exsolved within

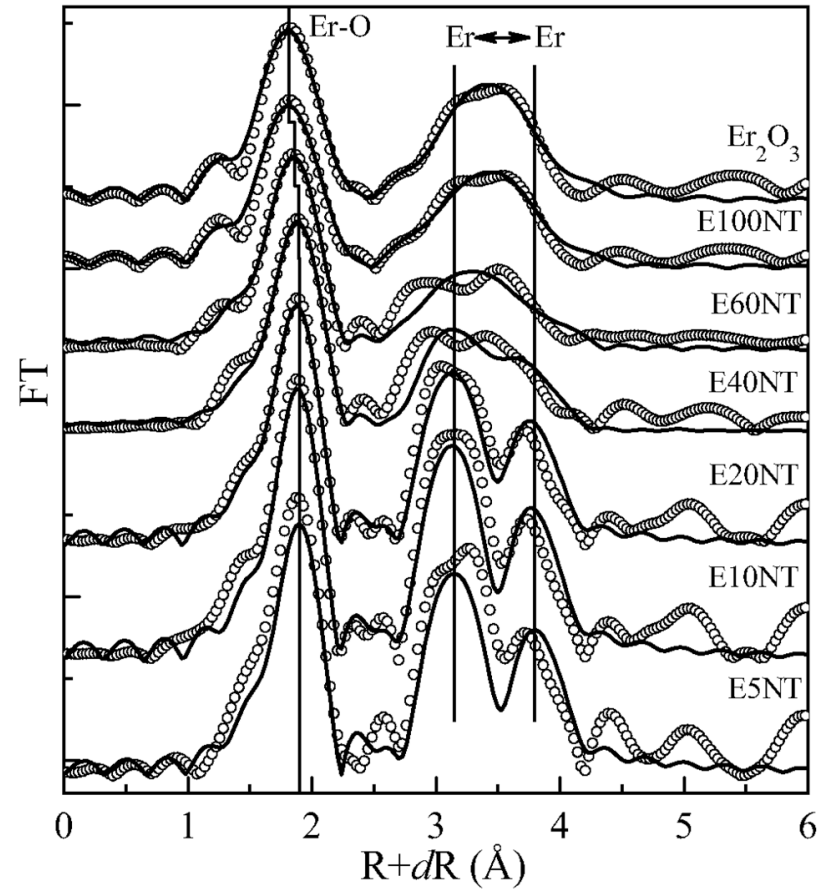

FIG. 7. (Color online) Fourier transformation (points) and corresponding fits (lines) of $k^{3}$-weighted Er $L_{\mathrm{III}}$-edge EXAFS of the $\mathrm{Er}^{3+}: \mathrm{Y}_{2} \mathrm{O}_{3}$ NTs with various doping levels after annealing the as-synthesized $\mathrm{Er}^{3+}: \mathrm{Y}(\mathrm{OH})_{3}$ NTs at $500{ }^{\circ} \mathrm{C}$ for $3 \mathrm{~h}$ and of the commercial $\mathrm{Er}_{2} \mathrm{O}_{3}$ powder.

the host $\mathrm{Y}_{2} \mathrm{O}_{3}$ phase. These features can be more readily observed in their Fourier transformations (FTs), which are shown in Fig. 7. All distances given in the discussion refer to actual interatomic distances (in angstroms). The corresponding FT peaks include a pair-dependent phase shift. FT peak positions are thus stated in terms of their phase-shifted distance, $R+\mathrm{d} R(\AA)$.

As shown in Fig. 7, the average position of the peak around $1.90 \AA, R+\mathrm{d} R$, for each $\mathrm{Er}^{3+}: \mathrm{Y}_{2} \mathrm{O}_{3}$ NT sample appears similar to that of the commercial $\mathrm{Er}_{2} \mathrm{O}_{3}$ powder reference, for which the first atomic polyhedron consists of six oxygen neighbors at average values of $2.26 \AA(4.5 \mathrm{O})$ and $2.33 \AA(1.5 \mathrm{O})$. This peak position shifts upward very slightly with the increase in $\mathrm{Y}$ content of the $\mathrm{Er}^{3+}: \mathrm{Y}_{2} \mathrm{O}_{3} \mathrm{NT}$ samples. This observation enables us to conclude that the erbium ions involved in $\mathrm{Er}-\mathrm{O}$ bonds are present as $\mathrm{Er}^{3+}$ cations. The other peaks above $2.50 \AA, R+\mathrm{d} R$, correspond to the more distant $\mathrm{Er} \leftrightarrow M_{k}$ cation neighbors at the nearest second shell. The FT of $\mathrm{Er}_{2} \mathrm{O}_{3}$ NT sample at the $\mathrm{Er} L_{\text {III }}$ edge is similar to that of the commercial $\mathrm{Er}_{2} \mathrm{O}_{3}$ powder sample, while the FTs of all other $\mathrm{Er}^{3+}: \mathrm{Y}_{2} \mathrm{O}_{3}$ NT samples at the Er $L_{\text {III }}$ edge are different from that of the commercial $\mathrm{Er}_{2} \mathrm{O}_{3}$ powder sample. When the concentration of $\mathrm{Y}$ increases (i.e., Er doping level decreases), the broad poorly resolved double FT peak corresponding to $\mathrm{Er} \leftrightarrow M_{k}$ paths more clearly splits into two separate peaks. The $\sim 3 \AA(R+\mathrm{d} R)$ peak shifts to lower $R$, consistent with the presence of $\mathrm{Y}$ atoms, which have contrasting backscattering phase and amplitude parameters as compared to $\mathrm{Er} \leftrightarrow \mathrm{Er}$, which is in the second shell of Er. This shift could also indicate a contraction of the interatomic distance. The higher- $R$ peak is attenuated and shifts to 
TABLE II. Structural parameters obtained from EXAFS fittings of the $\mathrm{Er}^{3+}: \mathrm{Y}_{2} \mathrm{O}_{3}$ NTs with various doping levels after annealing the as-synthesized $\mathrm{Er}^{3+}: \mathrm{Y}(\mathrm{OH})_{3} \mathrm{NTs}$ at $500{ }^{\circ} \mathrm{C}$ for $3 \mathrm{~h}$. Results from fitting of the $\mathrm{Er}_{2} \mathrm{O}_{3}$ reference powder are also shown to demonstrate the accuracy of the analysis. The standard deviation value for the last significant digit for each individual fit is shown in the parentheses. The EXAFS refinements give information about coordination number $(N)$, bonding distance $(R)$, distance between central element and the second shell element $(D)$, and thermal vibration $(D e b y e-W a l l e r$ factor, $\left.\sigma^{2}\right) \cdot e_{0}$ is the refined correction of the Fermi energy in vacuum, as compared to $e_{0}$ in SIXPACK. The statistical $R_{\text {res }}$ factor is defined in the text and gives an indication of the quality of fit in the $k$ space.

\begin{tabular}{|c|c|c|c|c|c|c|c|c|c|}
\hline \multirow[b]{3}{*}{ Parameter } & & & \multicolumn{7}{|c|}{ EXAFS fitting results } \\
\hline & \multicolumn{2}{|c|}{ XRD } & \multirow{2}{*}{$\begin{array}{l}\text { Powder } \\
\mathrm{Er}_{2} \mathrm{O}_{3}\end{array}$} & \multicolumn{6}{|c|}{ NTs } \\
\hline & $\mathrm{Y}_{2} \mathrm{O}_{3}{ }^{\mathrm{a}}$ & $\mathrm{Er}_{2} \mathrm{O}_{3}{ }^{\mathrm{b}}$ & & $\mathrm{Y}_{1.9} \mathrm{Er}_{0.1} \mathrm{O}_{3}$ & $\mathrm{Y}_{1.8} \mathrm{Er}_{0.2} \mathrm{O}_{3}$ & $\mathrm{Y}_{1.6} \mathrm{Er}_{0.4} \mathrm{O}_{3}$ & $\mathrm{Y}_{1.2} \mathrm{Er}_{0.8} \mathrm{O}_{3}$ & $\mathrm{Y}_{0.8} \mathrm{Er}_{1.2} \mathrm{O}_{3}$ & $\mathrm{Er}_{2} \mathrm{O}_{3}$ \\
\hline \multirow[t]{2}{*}{$R_{\mathrm{Er}-\mathrm{O}}$} & 2.277 & 2.256 & $2.24(1)$ & $2.25(1)$ & $2.25(1)$ & $2.25(1)$ & $2.26(1)$ & $2.25(1)$ & $2.25(1)$ \\
\hline & 2.335 & 2.334 & $2.33(1)$ & 2.33(1) & 2.33(1) & 2.33(1) & $2.34(1)$ & 2.33(1) & $2.33(1)$ \\
\hline$\sigma_{\mathrm{O}}^{2}$ & $\cdots$ & $\cdots$ & $0.007(1)$ & $0.004(1)$ & $0.003(1)$ & $0.004(1)$ & $0.005(1)$ & $0.006(1)$ & $0.007(1)$ \\
\hline$D_{\mathrm{Er}-\mathrm{Er} 1}$ & $\cdots$ & 3.496 & $3.51(1)$ & $3.51(1)$ & $3.50(1)$ & $3.50(1)$ & $3.50(1)$ & $3.50(1)$ & $3.51(2)$ \\
\hline$\sigma_{\mathrm{Er} 1}^{2}$ & $\cdots$ & $\cdots$ & $0.005(1)$ & $0.005(1)$ & $0.005(1)$ & $0.006(1)$ & $0.006(1)$ & $0.008(1)$ & $0.007(1)$ \\
\hline$D_{\mathrm{Er}-\mathrm{Y} 1}$ & 3.518 & $\cdots$ & $\cdots$ & $3.53(1)$ & $3.53(1)$ & $3.53(1)$ & $3.52(1)$ & $3.53(1)$ & $\cdots$ \\
\hline$\sigma_{\mathrm{Y} 1}^{2}$ & $\cdots$ & $\cdots$ & $\cdots$ & $0.005(1)$ & $0.005(1)$ & $0.006(1)$ & $0.006(1)$ & $0.008(1)$ & $\cdots$ \\
\hline$D_{\mathrm{Er}-\mathrm{Er} 2}$ & $\cdots$ & 3.985 & $3.98(1)$ & $3.99(1)$ & $3.97(1)$ & $3.98(1)$ & $3.97(2)$ & $3.97(2)$ & $3.98(2)$ \\
\hline$\sigma_{\mathrm{Er} 2}^{2}$ & $\cdots$ & $\cdots$ & $0.005(1)$ & $0.005(1)$ & $0.005(1)$ & $0.006(1)$ & $0.006(1)$ & $0.008(1)$ & $0.007(1)$ \\
\hline$D_{\mathrm{Er}-\mathrm{Y} 2}$ & 4.000 & $\cdots$ & $\cdots$ & 4.01(1) & $4.00(1)$ & $4.00(1)$ & $4.00(2)$ & $4.00(2)$ & $\ldots$ \\
\hline$\sigma_{\mathrm{Y} 2}^{2}$ & $\cdots$ & $\cdots$ & $\cdots$ & $0.005(1)$ & $0.005(1)$ & $0.006(1)$ & $0.006(1)$ & $0.008(1)$ & $\cdots$ \\
\hline$R_{\text {res }}$ factor & $\cdots$ & $\cdots$ & 0.0354 & 0.0858 & 0.0435 & 0.0300 & 0.0487 & 0.0366 & 0.0474 \\
\hline$e_{0}$ & $\cdots$ & $\cdots$ & -7.6384 & -4.8469 & -6.9333 & -7.3589 & -6.5447 & -7.9344 & -7.9513 \\
\hline
\end{tabular}

${ }^{\mathrm{a}}$ Reference 34.

${ }^{\mathrm{b}}$ Reference 31 .

higher $R$ values, also suggesting the presence of $\mathrm{Y}$ in the second shell and/or an expanded interatomic distance. Quantitative analysis of these EXAFS spectra was performed by using the model previously described, ${ }^{9}$ which apportions the number of second neighbor Er and $\mathrm{Y}$ atoms according to the mole fraction of Er/Y, i.e., assuming complete solid solution of $\mathrm{Er}_{2} \mathrm{O}_{3}$ in $\mathrm{Y}_{2} \mathrm{O}_{3}$. To further reduce the degrees of freedom in the fit, the $2.33 \AA$ Er-O shell was constrained to be $+0.085 \AA$ relative to the $2.25 \AA \mathrm{Er}-\mathrm{O}$ shell, $D_{\mathrm{Er}-\mathrm{Y} 1}$ was constrained to be $+0.025 \AA$ relative to $D_{\mathrm{Er}-\mathrm{Er} 1}$, and $D_{\mathrm{Er}-\mathrm{Y} 2}$ was constrained to be $+0.035 \AA$ relative to $D_{\mathrm{Er}-\mathrm{Er} 2}$ (Table II), based on the structures of $\mathrm{Y}_{2} \mathrm{O}_{3}$ and $\mathrm{Er}_{2} \mathrm{O}_{3}$. Reasonable curve-fitting results were obtained, as shown in Figs. 6 and 7 and summarized in Table II. The uncertainties from the fits for each $R$ value are estimated to be \pm 0.01 and $\pm 0.02 \AA$ for the first and second coordination shells, respectively. With variation in the doping level, the Debye-Waller factors remain almost the same, indicating that the level of disorder in these samples does not change much, which is consistent with our preceding XANES analysis. Similar phenomena were also reported for nanocrystalline $\mathrm{Tb}: \mathrm{Y}_{2} \mathrm{O}_{3}, \mathrm{Eu}: \mathrm{Y}_{2} \mathrm{O}_{3}$, and $\mathrm{Eu}: \mathrm{Lu}_{2} \mathrm{O}_{3} \cdot{ }^{12-14}$

As can be seen in Fig. 7, the EXAFS model reproduces all major features of the Er $K$-edge EXAFS spectra and FTs at high and low Er contents. At intermediate Er content (E40NT, E60NT), the apparent splitting of the second shell FT peaks between 3 and $4 \AA(R+\mathrm{d} R)$ is slightly underpredicted by the EXAFS model. From this behavior, we infer that the speciation of Er in these particular samples is controlled by mechanisms other than or in addition to the formation of solid solutions. This conclusion is not surprising, as complete solid solution between phases tends to be most limited in the middle of the compositional range.
These observations concerning the local dopant coordination environments of the erbium ions in $\mathrm{Y}_{2} \mathrm{O}_{3}$ host material have important consequences regarding the origins of the observed PL spectral features of the $\mathrm{Er}^{3+}: \mathrm{Y}_{2} \mathrm{O}_{3}$ NTs. It was shown for luminescent materials that the crystal structure and local coordination environment, and consequently the electronic structure of materials, have a profound effect on luminescent properties. ${ }^{9,12,13,24}$ Experimental studies demonstrated that an irregular distribution and ion immiscibility of RE ions can cause the spectral broadening and low PL efficiency. An irregular distribution of RE ions on lattice sites or occupancy of some Er ions on defect sites randomizes the Stark splitting, while ion immiscibility causes clustering or precipitating of RE ions within domains. These effects result in RE ions losing their luminescent and lasing properties. Especially, for the $\mathrm{Er}: \mathrm{SiO}_{2}$ system, it was found that $\mathrm{Er}^{3+}$ ions tended to cluster around the limited nonbridging $\mathrm{O}$ in the $\mathrm{SiO}_{2}$ network to screen their electric charge and consequently formed precipitates. ${ }^{35}$ In our case, the $\mathrm{Er}^{3+}$ ions do not participate in nonradiative quenching clusters if they are sufficiently isolated (i.e., low doping levels in $\mathrm{Y}_{2} \mathrm{O}_{3}$ ), or they could be paired (bridge through $\mathrm{O}$ ), but still be optically active, if two of them are in proximity (i.e., high doping levels in hosting $\mathrm{Y}_{2} \mathrm{O}_{3}$, or even pure $\mathrm{Er}_{2} \mathrm{O}_{3} \mathrm{NTs}$ ). Therefore, we observed remarkably sharp and well-resolved PL spectra from our as-synthesized Er: $\mathrm{Y}_{2} \mathrm{O}_{3}$ NTs. Furthermore, increasing the level of dopant concentration in our $\mathrm{Er}^{3+}: \mathrm{Y}_{2} \mathrm{O}_{3} \mathrm{NTs}$ produces only a modest structural disorder in the midcomposition range (as indicated by EXAFS). As higher levels of RE cations are doped into the NTs without a significant increase in disorder or defect density, there will likely be a greater number of optically active pairs of RE cations bridged through $\mathrm{O}$. This effect would cause a decrease in the overall 
PL efficiency per dopant in the NTs, but the PL spectra are still well resolved due to the regular distribution of $\mathrm{Er}^{3+}$ in the $\mathrm{Y}_{2} \mathrm{O}_{3}$ host material at both $C_{2}$ site and $C_{3 i}$ site. This is precisely what we have observed in our room temperature PL measurements (Fig. 1). ${ }^{6}$

\section{CONCLUSIONS}

Synchrotron-based XRD, XANES, and EXAFS have been used to study the local coordination environment of erbium dopant in erbium-doped yttrium oxide NTs prepared by a hydrothermal method followed a dehydration process. XRD, XANES, and EXAFS results have shown that (1) single phase solid solutions of $\mathrm{Y}_{(2-x)} \mathrm{Er}_{x} \mathrm{O}_{3}$ were formed at $x<0.4$ and $x>1.2$; (2) the valence state of $\mathrm{Er}$ ions in the doped $\mathrm{Y}_{2} \mathrm{O}_{3}$ NTs is +3 , indicating that the synthetic procedure, i.e., a hydrothermal process followed by a dehydration annealing, was able to retain the optically active trivalent state of erbium cation from its precursor state; (3) the erbium dopant resides largely in two types of sites of the $\mathrm{Y}_{2} \mathrm{O}_{3}$ host, both of which a possess well-defined intermediate-range structure; and (4) the doping of erbium into $\mathrm{Y}_{2} \mathrm{O}_{3}$ does not cause a loss in intermediate-range order and crystallinity in the $\mathrm{Er}^{3+}: \mathrm{Y}_{2} \mathrm{O}_{3}$ NTs. Furthermore, this study allows us to directly compare the local atomic structure of the RE-doped oxide material and its optical properties. These erbium-doped $\mathrm{Y}_{2} \mathrm{O}_{3}$ NTs exhibit well-resolved and sharp PL peaks at a wavelength of $\sim 1.535 \mu \mathrm{m}$, which validates the predictions of erbium ions occupying well-defined locations in the $\mathrm{Y}_{2} \mathrm{O}_{3}$ lattice. As this study establishes a direct correlation between the local atomic structure of the RE ions and the corresponding optical properties, it provides important insight on improving the optical properties of oxide materials in optoelectronic devices by engineering the RE ions' bonding environment and valence. Moreover, this study on $\mathrm{Er}^{3+}: \mathrm{Y}_{2} \mathrm{O}_{3}$ NTs would serve as a model system for probing the local dopant coordination environments and their correlation with PL spectral features.

\section{ACKNOWLEDGMENTS}

The authors acknowledge the financial and program support from the National Science Foundation (Grant Nos. DMII-0317449 and CTS0522534), the Office of Naval Research (a Young Investigator Award), and the Microelectronics Advanced Research Corporation (MARCO) and its Center on Functional Engineered NanoArchitectonics (FENA). The authors thank Monica Sawkar (UCLA), Joe Rogers (SSRL), and Dr. Sam Webb (SSRL) for fruitful discussions, and are also grateful to Dr. Roman Ostroumov and Professor Kang L. Wang (UCLA) for the PL measurements and Dr. Jian Y. Huang (CINT) for the TEM measurements. Portions of this research were carried out at the Stanford Synchrotron Radiation Laboratory, a national user facility operated by Stanford University on behalf of the U.S. Department of Energy, Office of Basic Energy Sciences. The SSRL Structural Molecular Biology Program is supported by the Department of Energy, Office of Biological and Environmental Research, and by the National Institutes of Health, National Center for Research Resources, Biomedical Technology Program.

${ }^{1}$ G. Blasse and B. C. Grabmeier, Luminescent Materials (Springer-Verlag, Berlin, 1994)

${ }^{2}$ T. Justel, H. Nikol, and C. Ronda, Angew. Chem., Int. Ed. 37, 3084 (1998)

${ }^{3}$ A. J. Steckl and J. M. Zavada, MRS Bull. 24, 16, (1999), and references therein

${ }^{4}$ F. Vetrone, J.-C. Boyer, and J. A. Capobianco, in Encyclopedia of Nanoscience and Nanotechnology, edited by H. S. Nalwa (American Scientific Publishers, Stevenson Ranch, CA, 2004), Vol. 10, p. 725.

${ }^{5}$ Z.-G. Wei, L.-D. Sun, X.-C. Jiang, C.-S. Liao, C.-H. Yan, Y. Tao, J. Zhang, T.-D. Hu, and Y.-N. Xie, Chem. Mater. 15, 3011 (2003).

${ }^{6}$ Y. Mao, J. Huang, R. Ostroumov, K. L. Wang, and J. P. Chang, J. Phys. Chem. C 112, 2278 (2008).

${ }^{7}$ A. J. Kenyon, Prog. Quantum Electron. 26, 225 (2002).

${ }^{8}$ C. Mignotte, J. Non-Cryst. Solids 291, 56 (2001).

${ }^{9}$ T. T. Van, J. R. Bargar, and J. P. Chang, J. Appl. Phys. 100, 023115 (2006).

${ }^{10}$ Y. Tao, G. Zhao, X. Ju, X. Shao, W. Zhang, and S. Xia, Mater. Lett. 28, 137 (1996)

${ }^{11}$ M. H. Nilsen, C. Nordhei, A. L. Ramstad, D. G. Nicholson, M. Poliakoff, and A. Cabanas, J. Phys. Chem. C 111, 6252 (2007).

${ }^{12}$ Z. Qi, C. Shi, W. Zhang, W. Zhang, and T. Hu, Appl. Phys. Lett. 81, 2857 (2002).

${ }^{13}$ Y. L. Soo, S. W. Huang, Z. H. Ming, Y. H. Kao, G. C. Smith, E. Goldburt, R. Hodel, B. Kulkarni, J. V. D. Veliadis, and R. N. Bhargava, J. Appl. Phys. 83, 5404 (1998).

${ }^{14}$ Z. Qi, M. Liu, Y. Chen, G. Zhang, M. Xu, C. Shi, W. Zhang, M. Yin, and Y. Xie, J. Phys. Chem. C 111, 1945 (2007).

${ }^{15}$ Y. L. Soo, S. W. Huang, Y. H. Kao, V. Chhabra, B. Kulkarni, J. V. D. Veliadis, and R. N. Bhargava, Appl. Phys. Lett. 75, 2464 (1999).

${ }^{16}$ T. T. Van, J. Hoang, R. Ostroumov, K. L. Wang, J. R. Bargar, J. Lu, H.-O. Blom, and J. P. Chang, J. Appl. Phys. 100, 073512 (2006).

${ }^{17}$ B. K. Teo, EXAFS: Basic Principles and Data Analysis (Springer-Verlag, New York, 1986).

${ }^{18}$ F. W. Lytle, J. Synchrotron Radiat. 6, 123 (1999).

${ }^{19}$ F. de Groot, Chem. Rev. (Washington, D.C.) 101, 1779 (2001)

${ }^{20}$ B. D. Yuhas, S. Fakra, M. A. Marcus, and P. Yang, Nano Lett. 7, 905 (2007).

${ }^{21}$ D. Carta, G. Mountjoy, G. Navarra, M. F. Casula, D. Loche, S. Marras, and A. Corrias, J. Phys. Chem. C 111, 6308 (2007).

${ }^{22}$ S.-J. Hwang and J.-H. Choy, J. Phys. Chem. B 107, 5791 (2003).

${ }^{23}$ P. Ghosh, K. R. Priolkar, and A. Patra, J. Phys. Chem. C 111, 571 (2007).

${ }^{24}$ F. d'Acapito, S. Mobilio, P. Bruno, D. Barbier, and J. Philipsen, J. Appl. Phys. 90, 265 (2001).

${ }^{25}$ W. Li, A. I. Frenkel, J. C. Woicik, C. Ni, and S. I. Shah, Phys. Rev. B 72, 155315 (2005).

${ }^{26}$ M. Fernandez-Garcia, A. Martinez-Arias, J. C. Hanson, and J. A. Rodriguez, Chem. Rev. (Washington, D.C.) 104, 4063 (2004).

${ }^{27}$ T. T. Van and J. P. Chang, Appl. Phys. Lett. 87, 011907 (2005).

${ }^{28}$ S. M. Webb, Phys. Scr., T T115, 1011 (2005).

${ }^{29}$ Z. Y. Wu, C. M. Liu, L. Guo, R. Hu, M. I. Abbas, T. D. Hu, and H. B. Xu, J. Phys. Chem. B 109, 2512 (2005).

${ }^{30}$ X. Chen, Q. Cai, W. Wang, Z. Chen, Z. Wu, Z. Wu, C. Feng, and Q. Li, J. Phys. Chem. C 111, 4512 (2007).

${ }^{31}$ M. Ishii, S. Komuro, T. Morikawa, Y. Aoyagi, T. Ishikawa, and T. Ueki, Jpn. J. Appl. Phys., Suppl. 38-1, 191 (1999).

${ }^{32}$ M. Malvestuto, R. Carboni, F. Boscherini, F. D’Acapito, S. Spiga, M. Fanciulli, A. Dimoulas, G. Vellianitis, and G. Mavrou, Phys. Rev. B 71, 075318 (2005)

${ }^{33}$ M. Mitric, A. Kremenovic, R. Dimitrijevic, and D. Rodic, Solid State Ionics 101, 495 (1997).

${ }^{34}$ A. Saiki, N. Ishizawa, N. Mizutani, and M. Kato, J. Ceram. Soc. Jpn. 93, 649 (1985)

${ }^{35}$ K. Arai, H. Namikawa, K. Kumata, and T. Honda, J. Appl. Phys. 59, 3430 (1986).

${ }^{36}$ JCPDS Card No. 41-1105 (unpublished).

${ }^{37}$ JCPDS Card No. 01-0827 (unpublished). 